\title{
Problems for a Modal Epistemology
}

\section{Rebecca Hanrahan \\ Whitman College}

I drive a little too fast when coming home from work. As I am about to drive through a particularly tight curve, often an image comes before my mind's eye of a bicyclist just beyond the bend. To avoid the possibility of a collision, I slow down. Other times, as I am looking in my rear view mirror, an image of a police car's flashing blue lights comes to mind. This image immediately causes me to take my foot off the gas to avoid the possibility of a speeding ticket. Here are two everyday examples of my using conceivability as a guide to possibility. Because I assume that these images provide me with a guide to possibility, I decelerate. But why think conceivability can provide me with such a guide? That is, why think that my conceiving of a certain state of affairs shows (or even provides prima facie evidence) that that state of affairs is possible?"'

This question has gotten much attention lately. But those who are seeking its answer are often doing so in the service of some larger cause. As a consequence, they define conceivability quite nar-

'Some might argue that in these examples I am not using conceivability as a guide to possibility, rather I am using conceivability as a guide to probability. I decelerate not because it is possible that there is a police car tailing me, I decelerate because there is the real chance that a police car is behind me and these images are just reminding me of this fact. But when we are dealing with such everyday possibilities the possible and the probable blend together. That is, when we wonder what could happen to us in the near future, whatever we deem possible, we often can't help but consider probable. Moreover, prior to our determining that an event is probable, we must first establish that that event is possible. In what follows, I want to show how the images we call forth can help us in this task. 
rowly. Consider, for example, the debate within the philosophy of mind between David Chalmers and Frank Jackson on one hand and Ned Block and Robert Stalnaker on the other. ${ }^{2}$ The question at issue here is whether physicalism requires the $a$ priori deductibility of mental facts from physical facts. In terms of this debate, conceivability is then defined negatively: $p^{\wedge} \sim q$ is conceivable just in case $q$ cannot be deduced from $p$ using logical and conceptual truths. ${ }^{3}$ Regardless of the outcome of this debate, nothing here will tell me if or how my ability to call forth images of flashing blue lights justifies my belief that it is possible that a police car is behind me.

This is because this notion of conceivability doesn't include a sensory component. In fact, most of the recent literature on the relationship between conceivability and possibility has largely ignored the role the sensory imagination can play within a modal epistemology. Both Chalmers and Ernest Sosa, for example, consider the ability to imagine as one of the methods by which we can conceive of a proposition. ${ }^{4}$ Sosa even makes the further claim that the imagination may "perhaps provide a distinctive source of justification," but he does not support this claim with an argument. ${ }^{5}$ And Chalmers forgoes a sustained discussion of the question as to whether the imagination provides us with a guide to possibility by noting that conceivability outstrips our ability to call forth mental images. But, in the above examples, it would seem that it is at least in part my ability to call forth images of a bicyclist and

${ }^{2}$ See Ned Block and Robert Stalnaker, "Conceptual Analysis, Dualism, and the Explanatory Gap," The Philosophical Review 108 (1999): 1-46. See also David Chalmers and Frank Jackson, "Conceptual Analysis and Reductive Explanation," The Philosophical Review 110 (2001): 315-361.

${ }^{3}$ This is the second of Block and Stalnaker's two notions of conceivability. The first is less explicit but even more narrow, explained entirely in terms of natural kind terms like 'water' and their reference on Twin Earth. See Block and Stalnaker (1999): 6-7. Katalin Balog also gives an equivalent formulation in her article "Conceivability, Possibility, and the Mind-Body Problem," The Philosophical Review 108 (1999): 498.

${ }^{4}$ See Ernst Sosa, "Modal and Other A Priori Epistemology: How Can We Know What Is Possible and What's Impossible?" The Southern Journal of Philosophy (Vol. XXXVIII, Suppl. 2000); and David Chalmerș, "Does Conceivability Entail Possibility?" Conceivability and Possibility, edited by Tamar Szabo Gendler and John Hawthorne, (Oxford: Oxford University Press, 2002): 145-200.

${ }^{5}$ Sosa (2000): 2. 
police lights that justifies my belief that I should slow down. Thus, I want to develop a modal epistemology that depends on the imagination. Doing so will provide us with a much needed account of our everyday uses of conceivability as guide to possibility.

Unfortunately, any modal epistemology that depends on the imagination will suffer from the problem of indeterminacy. In most cases, when we imagine proposition ( $p$ ) whatever image we call forth will be indeterminate and this indeterminacy will preclude us from concluding that we have conceived of what we intended to conceive, viz., p. Consequently, we can't draw any conclusion about p's modal status from the images we have called forth. Thus, conceivability here can't provided us with a guide to possibility.

In response, I will argue that if we allow inferences to our best explanation to play virtually the same role in justifying our modal claims as they play in justifying our claims about what is actual, in certain cases we will be able to meet this objection and we will also be able to explain how conceivability can provide us with a guide to possibility. But this response courts another common objection; the problem of incompleteness. Because of our limited mental capabilities, we can't conceive of everything that pertains to $p$. Thus, whatever we conceive will always be incomplete. Consequently, we can't be sure that a contradiction or incoherence wouldn't be revealed if we had conceived of this proposition completely. Thus, again, we can't draw any conclusions about what is possible based on what we have conceived.

Clearly, the problems of indeterminacy and incompleteness are my Scylla and Charybdis. Thus I begin the paper by discussing each of these objections in detail. I will then offer a solution to the problem of indeterminacy that employs inferences to our best explanation. I will next explain how conceivability can provide us with a guide to the modal status of some propositions. Finally, after considering some counterexamples to my theory, I will offer a response to the problem of incompleteness. ${ }^{6}$

${ }^{6} \mathrm{~A}$ note is in order about the notion of possibility at play in this paper. As Gendler and Hawthorne point out, conceivability is most often taken to be a guide to what they call 'metaphysical possibility,' which concerns the "ways things might have been." Thus, to say that $p$ is possible is just to say that there is a possible world in which $p$ is true. And each possible world is described or 


\section{Objection One: Indeterminate Images}

As I have said, the indeterminacy objection arises when, in order to provide ourselves with a guide to p's modal status, we conceive of $p$ via our imagination. It is commonly thought that to imagine $p$, one must call forth an image or a series of images of some state of affairs in which $p$ is true. So, to imagine myself doing yoga, I might call forth images of myself assuming the down-dog position and then the crouching-tiger-hidden-dragon position. Now, via this method, it seems we can conceive of the impossible. For example, we can seemingly imagine a table whose top is both circular and square by calling forth an image of such a table viewed from its side. ${ }^{7}$ But if we can imagine the impossible, then this method of conceiving can't provide us with a guide to possibility.

One way to undermine this argument is to challenge the above example with the hope of showing that it isn't in fact an instance of our imagining the impossible. Consider then the image we call forth when we try to imagine this table. Because we are picturing this table from its side, the tabletop in this image will be depicted by not much more than a straight line. Clearly, this image is indeterminate. It is just as much an image of a round-square table as it is an image of a table with a triangular or rectangular top. Consequently, we can't conclude that we have imagined a round-square table here. And if we can't conclude this, then, obviously, we can't conclude that we have imagined the impossible.

The problem with this counter-argument is that it sinks the ship it is trying to save. While indeterminacy does affect this image, it also affects all of the images we can ever call forth of a particular object, person, or substance. I am currently sitting at my desk, starring out the window into my backyard. Say that I try to imagine the following proposition

(F) My father is mowing my lawn.

constituted by a complete and consistent set of propositions. In what follows, it is this wide sense of possibility that is intended. Tamar Szabo Gendler and John Hawthorne, "Introduction," Conceivability and Possibility, (Oxford: Clarendon Press, 2002): 5.

${ }^{7}$ Paul Tidman offers a version of this example. See Tidman, "Conceivability as a Test for Possibility," American Philosophical Quarterly 31 (1994): 300. 
And I call forth a series of particularly forceful and vivacious images of a man that looks like my father sitting on a John Deere cutting my grass. Can I conclude that I have imagined F? Given the standards implied above, I can't. These images are also indeterminate. They could be images of my father, but they could just as well be images of my Uncle Bill who looks an awful lot like my father. Nothing about these images in and of themselves precludes this interpretation. Thus, I can't conclude that I have imagined F. ${ }^{8}$

When imagining $p$, in most every case there will be some sort of similar indeterminacy associated with the images we have called forth. Such indeterminacy will give us reason to question whether

${ }^{8}$ Some have argued that this objection can be solved by noting how causal facts can determine the content of an image. Rembrandt's self portrait, for example, is clearly of Rembrandt because he was painting himself when painting this portrait. But consider the case of my uncle and my father. As I noted above, the two look very much alike, so much so that when considering family photos I at times can't tell if the picture in hand is of my father or of my uncle. Now, I have all sorts of images of my family stored in my head. Let's say that I am asked to imagine my dad and I call forth an image and it is an image that looks like my dad, but also like my uncle. I don't know why this image came up as opposed to another. I also don't know if I stored this image correctly under the "father" file in my mind's file cabinet. Worse yet, I don't know if this is a composite picture or a memory. If it is a composite, if I in some way constructed this picture, I don't know how and what images I used as parts. The point here is that I don't know much about the causal process that produced this (or any) image and because I don't have this information I don't know how causal facts can help me determine the content of an image.

To this, some might reply that these aren't the causal facts at issue. Rather, it is my knowledge of my own intentions and in addition, the knowledge I have about my own experiences that determine the content of my imagined images. I discuss the role intentions can play in determining the content of one's imagination in footnote 18. As to the information I have about my own past experiences, it seems as if the process by which such information would determine the content of an imagined images would be similar to the process I describe in my own solution to the problem of indeterminacy, viz., a process involving inferences to the best explanation. (See the section entitled "Indeterminacy and Inferences to the Best Explanation.") Thus, either I don't have the causal information I need to determine the content of my imagined images, which leaves the problem of indeterminacy unaddressed, or I do have it, and it is this very information I employ to address the problem of indeterminacy when I account for an image via my best explanation. 
these images are really of a state of affairs in which $p$ is true. And, of course, if we are trying to imagine $p$ for the purpose of providing ourselves with a guide to possibility and yet we can't tell whether we have imagined $p$, we surely can't draw any conclusions about p's modal status based on what we have imagined. Thus, for this reason, our imagination can't provide us with a guide to possibility. ${ }^{9}$

\section{Objection Two: Incomplete Stories}

The problem of incompleteness, like the problem of indeterminacy, primarily arises in response to our employing a specific method of conceiving as our guide to possibility. But in this instance the method of conceiving at issue isn't our ability to imagine; rather, it is our ability to tell stories. Now, while my modal epistemology does depend on our sensory imagination, story telling will also be relevant. This means my epistemology will also have to address this objection. So let's also begin this section by considering the specifics of this method of conceiving and then turn to this objection.

To conceive of $p$ via this method, one must tell a story or describe some state of affairs in which $\mathrm{p}$ is true. Minimally, this story is to describe some of the conditions associated with p's truth. So, for example, to imagine that my brother married his Bulgarian sweetheart in a shotgun ceremony, I must tell a story either about how he came to marry this woman, what the wedding was like, and/or what happened to Richard and Svetlana after their nuptials.

To say that $p$ is possible is to say that there is a possible world in which $p$ is true, where that possible world is understood to be described or constituted by a maximally consistent set of propositions which contains $p$. Given this, if we could tell a story in which we described all the conditions necessary for $p$ 's truth, then we could come to a conclusion about p's modal status from what we had con-

${ }^{9}$ The indeterminacy objection is discussed by James van Cleve, "Conceivability and the Cartesian Argument for Dualism," Pacific Philosophical Quarterly. 64 (1983): 36; Tidman (1994): 298-301; Christopher Peacocke, "Imagination, Experience, and Possibility: A Berkeleian View Defended," Essays on Berkeley, edited by J. Foster and H. Robinson (Oxford: Oxford University Press, 1985): 19-35, and Stephen Yablo, "Is Conceivability a Guide to Possibility," Philosophy and Phenomenological Research, vol. LIII, no. 1 (1993): 27-30. 
ceived. For if in telling such a story we encountered no contradictions, for all intents and purposes we would have described a possible world in which $\mathrm{p}$ was true. Thus, given the above definition, we would have established that $p$ is possible.

But the problem here is clear. We can't describe all the conditions that are necessary for p's truth. For such a set of propositions is infinitely large. We can describe some of these conditions. But such a description is an inadequate basis from which to draw conclusions about p's modal status. For this shortened description might hide some contradiction or incoherence that would have been revealed if this description had been completed. And, of course, such a discovery would force us to conclude that the world we were describing wasn't in fact a possible world. Thus, no conclusions can be drawn about p's modal status from this shortened description.

Take, for example, the proposition

(T) Yesterday I traveled back in time.

I can tell a story about how yesterday morning I blasted off in a special spaceship whose maximum speed exceeded the speed of light, how I then decided to fly to $79 \mathrm{AD}$ in order to witness the destruction of Pompeii, how I eventually tired of the spectacle, and thus headed for home, returning in time for dinner. But this story clearly falls short of a complete description of a possible world. Hence, I can't conclude that $T$ is possible. For if $I$ extended this story to include more of the consequences of T's truth, I would discover a host of contradictions. I would discover that I could prevent myself from ever existing, that future events caused past events, and that time no longer worked as it was supposed to work. Thus, I can't base my conclusion that $T$ is possible on this shortened story.

So any story we tell will always be incomplete. It will never contain all of the conditions associated with p's truth. Hence, a contradiction or incoherence may remain hidden that would reveal the proposition in question to be impossible. Thus, we can't conclude that $p$ is possible given the stories we tell about $p^{.10}$

${ }^{10}$ The problem of incompleteness is discussed by Tidman (1994): 303-305. 


\section{Proof vs. Justification}

Unfortunately, both the problem of indeterminacy and the problem of incompleteness are unsolvable. To quickly review: if we are conjuring up images of $p$ where $p$ concerns a specific object, person, or substance, the images we call forth will always be indeterminate. If instead we try to conceive of $p$ via a story, that story will never constitute a complete description of a possible world. Thus, given these problems, we must conclude that our ability to conceive of $p$ via these two methods doesn't provide us with proof that $p$ is possible.

Note though that one of my goals for this paper is to defend the claim that conceivability provides us with a guide to possibility. For conceivability to function as a guide, it need not provide us with proof. If instead it merely enabled us to justify our beliefs in regards to what is possible, that in itself would constitute a guide. Thus, we will now move away from notions of proof to the less stringent notion of justification." Of course, making this move won't, by itself, solve either of our two objections. Rather these objections get moved as well. That is, the questions now before us are 1.) How and why do the images I call forth justify my belief that $p$ is possible, despite the fact that these images are indeterminate? And 2.) How and why does the story I tell justify my belief that $p$ is possible, despite the fact that $p$ might imply a contradiction not uncovered by my story?To answer these questions, we need to consider how we deal with indeterminacy when it arises in other contexts. If we do this, we will see how our two objections can both be addressed and how conceivability can in some cases provide us with a guide to possibility.

\section{Indeterminacy and Inferences to the Best Explanation}

The problems associated with indeterminacy don't just arise when we try to justify our beliefs about what is possible. They also arise when we form beliefs based on our perceptions. Over Winter Break, I went to Washington to visit my brother. As I walked through

"Justification is defeasible. Thus, via my modal epistemology I might be justified in believing that $p$ is possible, when it isn't. Such failures don't necessarily indicate that my theory is flawed; rather, they are a consequence of the move from proof to justification. 
the airport, I spied a man some ways away who looked an awful lot like my father. As far as I knew, my father wasn't going to be in the Capitol. But my uncle was, for he lives near and works in Washington. Despite this, I contend that I was justified in believing that it was my father I was seeing. Why was this? Why didn't my beliefs about my uncle (in combination with the fact that he resembles my father) undermine my justification that it was my father standing at the gate to Concourse $\mathrm{C}$ ?

My belief here wasn't undermined because I have an account of my relationships with the different members of my family and it is this account that in part justifies my taking these perceptions to be of my father. I know that my father is the kind of man who would hop on a plane bound for Washington to surprise his children. I also know that my uncle wouldn't ever feel the need to meet me at the airport. For these reasons, I was justified in believing that it was my father waiting for me, as opposed to my uncle. ${ }^{2}$ Problems with indeterminacy arise at virtually every moment of our waking lives. It appears to me as if there are trees outside my window but these perceptions could equally well be perceptions of plastic fakes. Nothing in these perceptions themselves can tell me which is the case. But even though such problems are omnipresent, we can in some cases

${ }^{12} \mathrm{I}$ am arguing that my belief that it was my father standing at the gates to Concourse $C$ and not my uncle was justified via an inference to my best explanation. But, some might argue, the person at Concourse $C$ was most likely a complete stranger, who just resembled my kin. Given this, how then was I justified in believing that it was my father as opposed to a stranger?

In response to this objection, note that justification comes in degrees. Thus, depending upon what laws and relationships compose my best explanation, I might be forced to concede that I would have been more justified in believing that it was a complete stranger than in believeing that it was my father. But this concession doesn't prevent me from arguing that given that same best explanation I was more justified in believing that it was my father than in believing that it was my uncle. Of course, I don't want to make any such concession. The best explanation I have of the fact that two or more people resemble each other in multiple ways is that the people in question are related. Thus, because this man at the gates to Concourse $C$ looked an awful lot like me, I was more justified in believing that he was a relation than a stranger. And then for various reasons detailed above I was more justified in believing that he was my father than my uncle. (See footnotes 16,18 , and below.) I would like to thank the referee for this journal for bring this objection to my attention. 
swiftly and easily move around them via inferences to our best explanation. Each of us has an explanation of how this world works. And it is via this explanation that we justify many of our beliefs and at times ameliorate the indeterminacy of our perceptions. While my images ${ }^{13}$ of the things outside the window are, considered in themselves, indeterminate between real and plastic trees, my best explanation justifies my belief that they represent real trees. ${ }^{14}$

So, when justifying our beliefs about the actual world, inferences to our best explanation enable us to negotiate problems of indeterminacy (among other things). Might these same kinds of inferences help us with the indeterminacies that arise when we seek to justify our beliefs about what is possible? I contend that they do.

Return to the example of my trying to imagine a round-square table in which an image of a table viewed from the side comes before my mind's eye. Say this image came to me and yet I didn't know its origins. In other words, say that while this image was quite forceful and vivacious, ${ }^{15}$ I didn't know whether I had imagined it: whether it was a veridical perception, or whether it was an optical anomaly. Under these circumstances, would I be justified given my best explanation in concluding that this image was a veridical perception of a

${ }^{13}$ At times I use the word 'image' broadly to refer to those sensory experiences that can be produced via multiple means, i.e. via the imagination, perception, optical anomalies, and hallucination. At other times, I use the word 'image' to refer more narrowly to an image produced specifically through the imagination. I have specified which sense I mean only when context does not suffice.

"In an earlier paper, I explore both the role inferences to the best explanation play in perception and the relationship between the imagination and perception. There I highlight the minimal nature of the claim being made above. I am only claiming that such inferences are one of the tools we employ to address issues of content when perceiving. I also emphasize that such inferences are only made explicit when challenged or when we discover that the belief at issue, while justified, is in fact false. In the present paper, I again discuss these inferences and this relationship, though briefly. See Rebecca Hanrahan, "Imagination and Possibility," Philosophical Forum, vol. XXXVIII, no. 2, Summer 2007.

${ }^{15}$ I hold that sensory mental states such as imagined images and percepts have qualities that vary in degrees. What qualities these are and how they are best described is not important to my theory. Above I work with the notions of force and vivacity for the sake of convenience and tradition. 
round-square table? No, I wouldn't. Given what I know of tables and shapes, I know that I can't draw any conclusions about the shape of this table when seeing it from its side. Thus, not only can't I conclude that this is a round-square table, I can't conclude that this table is triangular, circular, or square. In this case, my best explanation precludes me from concluding that I have imagined what I intended to imagine.

But what of the images I call forth when I try to imagine my father mowing the lawn? What does my best explanation tell me about these images, which were also quite forceful and vivacious? If these images had come to me and again I didn't know their origins, then given my best explanation I would be justified in taking these images to be veridical perceptions of my father. In fact, my best explanation would demand that I draw this conclusion, for if I took these images to be of my uncle, the account I would have of them would be too complicated. After all, my father lives down the street from me, and he nags me constantly about my failure to maintain my house's 'curb appeal.' I can easily tell a story about him getting fed up with my laziness and mowing my lawn for the sake of the neighborhood. In addition, my uncle lives near DC and cares not for machines or lawn care. Thus, I would have to tell a convoluted story to get him on my mower. ${ }^{16}$

Thus, we have an in principle way of dealing with some of the indeterminate images we call forth. Say I want to justify my belief that $p$ is possible and I call forth a series of images. I can ask of these images the following question: If the origin of these images were unknown to me, could I (given my best explanation) justify taking

${ }^{16}$ The fact that I can within the confines of my best explanation tell a convoluted story that would have it be my uncle on the John Deere Mower as opposed to my father means that I would be justified in taking these images to be of my uncle. But in so far as this story is convoluted as compared to the story I can tell about my father means that $I$ am less justified in taking these images to be of my uncle and more justified in taking these images to be of my father. And, of course, abduction like any other justificatory inference demands that I seek to provide myself with the best justification I can, unless there is good reason to settle for less. And there is no such reason here. Hence, abduction demands that I take these images to be of my father. See as well footnote 12, 18 , and below. 
these images to be veridical perceptions of $p$ ? If I could, then regardless of the fact that these images are indeterminate, I would be justified in concluding that $I$ had imagined $\mathrm{p}$.

What I have done above is place a requirement on the imagination when seeking to justify our belief that $p$ is possible. Specifically, the images we call forth must be such that given our best explanation these images could be taken to be veridical perceptions of $p$ (if their origins were unknown). It shouldn't be surprising that such a specific requirement is in place here. Often when we seek to justify a particular kind of belief, there are requirements to be met that are more stringent than those in place in different contexts. (To justify many of our scientific beliefs, for example, our observations must be made in controlled settings.) It also shouldn't be surprising that this is the requirement we must meet. It has been said that the imagination is to the possible as perception is to the actual. ${ }^{17}$ If this analogy is illuminating, then the same requirements placed on us when we employ our perceptions to justify our beliefs about the actual world might be operative when we employ our imagination as a guide to possible worlds. Obviously, inferences to our best explanation have a role in justifying our beliefs about the actual world and, as I will show, such inferences can play a similar role when justifying our beliefs about possible worlds. ${ }^{18}$

${ }^{17}$ See Peacocke (1985): 31; Yablo (1993): 5; and W. D. Hart, The Engines of the Soul, (Cambridge: Cambridge University Press, 1988): 15.

${ }^{18}$ Might there be a simpler way to address this problem of indeterminacy? In "Conceivability as a Test for Possibility," Paul Tidman contends that though imagined images are indeterminate, this indeterminacy is irrelevant, for it is our intentions that determine the content of our imagination.

But consider that the imagination is contentful. When we imagine, we always imagine something, a person, place, or thing, for instance. Next consider that to imagine anything, we must call forth images. If Tidman is right, these images won't do any work in determining the content of what we have imagined. Say I intend to imagine the rebuilding of the Berlin Wall and the images that come before my mind's eye resemble a tomato. In this situation, despite what my images seem to be images of, viz., a tomato, I will have successfully imagined the rebuilding of this wall. But this seems wrong. If imagining is a contentful activity that essentially involves the calling forth of images, these images must have some role in determining the imagination's content. Of course, this conclusion doesn't preclude our intentions playing some role in determining this content; my claim so far is only that they do not by themselves determine content. 
An objection, though, arises at this point. I am trying to negotiate a way around the problem of indeterminacy. And I argue that I can avoid this problem if the images I have called forth are such that I would take them to be veridical perceptions if these images had come to me in such a way that I didn't know their origin. But since I assumed that these images possessed high degrees of force and vivacity, it is no surprise that I would take these images to be veridical. For high degrees of these very qualities is what marks an image as veridical. Thus, in making this assumption, it seems I have begged the question.

In response to this objection, let me first clarify the position I hold. My position is that from the first person perspective the images that come to us via our imagination can at times possess the same sorts of qualities as the percepts that come to us via our senses. ${ }^{19}$ An imagined image can be just as forceful and vivacious as a percept and sometimes a percept can lack these qualities in the way that images do. ${ }^{20}$ Thus, percepts and images aren't intrinsically different from each other from the first person perspective. That said, they are intrinsically different from a third person perspective. The causal processes that produce an image are different from the causal processes that produce a percept; one involves the conscious will, the other does not. Moreover, though from a first person perspective there is no intrinsic difference between these sorts of mental states,

As I see it, our intentions define the parameters under which we are to query the image under consideration. That is, upon calling forth an image, I must ask whether, if this image's origin were unknown to me, I would be justified in taking that image to be a veridical perception of that which $I$ had intended to imagine, viz., p. If I would be, then I am justified in taking that image to be of $\mathrm{p}$. And I am so, even if that image could under different parameters be taken to be of something other than p. See Tidman, (1994): 301 and Rebecca Hanrahan, "Epistemology and Possibility," Dialogue, vol. XLIV, no. 4, Fall 2005.

${ }^{19}$ Shoemaker distinguishes two different senses behind the notion of the 'first person point of view.' My notion is most akin to the first. That is, when I speak of the first person perspective, I speak of "some aspect of the life of a person as it might be experienced by that person" as opposed to speaking of "oneself doing or undergoing such and such" from the inside. See Sydney Shoemaker, "The First Person Perspective," The Nature of Consciousness: Philosophical Debates, edited by N. Block et. al. (Cambridge: MIT Press, 1998): 511.

${ }^{20}$ See footnote 15. 
in general percepts do possess higher degrees of force, vivacity, and determination than imagined images.

Note that, historically, the position I am offering here-that from the first person perspective our imagined images aren't intrinsically different from our percepts and hence can at time possess the same qualities as our percepts-is the standard empiricist position. Note as well that this position is common within the contemporary literature on the imagination. ${ }^{21}$ Some may balk at the relationship being drawn here between our imagination and perception. But at times we have all been confused about the origin of the image before our mind's eye. We have wondered if we are really seeing what we are seeing or if instead we are just imagining, or are subject to some trick of light. Some argue that such confusions aren't even all that uncommon. As William Lycan says, "[p]utting anomalies down to sensory delusion, lapse of memory, or faulty computation is both easier and more prevalent than might be thought."22 But if we accept that we can be confused in this way, we also have to accept that such confusions are dependent on the fact that we can at times have images come to us via our imagination or via some optical illusion that possess the same qualities as those we have taken to be veridical.

Moreover, the claim that there is no one property or sets of properties available from the first person perspective that determinately

${ }^{21}$ Colin McGinn states that there is one "non-negotiable fact about images: ... they bear a phenomenological resemblance to percepts." He further argues that "maybe images are typically more indeterminate than percepts, but both seem to admit of some indeterminacy; if so, there is no ground for a sharp distinction here." (Colin McGinn, Mindsight: Image, Dream, Meaning, (Cambridge, MA.: Harvard University Press, 2000): 41 and 25.) Similarly, Amy Kind argues that "perceiving and imagining are so experientially similar that the former is sometimes mistaken for the latter." (Amy Kind, "Putting the Image Back in Imagination," Philosophy and Phenomenological Research, vol. LXII, no 1 (2001), 94.) Finally, Gregory Currie and Ian Ravenscroft write, "The seeing and the visualizing have the same contents; the visualizing, moreover, has a visual character. We need invoke no more than this to explain our intuition that seeing and visualizing are similar, and facts about our limited capacity to discriminate between them." (Currie, Gregory and lan Ravenscroft, Recreative Minds (Clarendon Press: Oxford, 2002): 28.)

${ }^{22}$ William Lycan, “Occam's Razor," Judgment and Justification (Cambridge: Cambridge University Press, 1988): 126. 
distinguishes the one kind of sensory mental state from another is behind Descartes's dream argument and skepticism in general. Skepticism arises precisely because there is no intrinsic mark or 'criterion' that from the first person perspective indicates the source of our sensorial mental states. Thus, to reject my position is to render skepticism a non-problem. I don't think we want to solve skepticism so easily. Thus, we have to accept that our imagined images aren't intrinsically different from our percepts and hence can from the first person perspective share the same qualities. ${ }^{23}$

So, now we can see how we can in some instances justify our taking the images we call forth to be images of $p$, despite the fact that these images are indeterminate. We are so justified if, upon ignoring the fact that we willed these images, we could account for them as veridical perceptions given our best explanation. Thus, I have addressed the problem of indeterminacy. I have also clarified the ways in which percepts and images are alike from a first person perspective. But I haven't yet explained how conceivability can provide us with a guide to possibility, nor have I addressed the problem of incompleteness. To accomplish these tasks, we need to consider in more detail inferences to our best explanation.

\section{Conceivability as a Guide to Possibility}

Return to the airport. My belief that it was my father standing at the security gate was justified because via my best explanation I

${ }^{23}$ It could be argued that to preserve skepticism as a problem, we need only acknowledge that that there are no intrinsic differences between our hallucinations and our percepts. And we can hold this position, while contending that our imagined images are intrinsically different from our percepts. This is correct. Note, though, that those who hold this position are conceding that the products of our imagination can possess all the same qualities as our percepts, but only when those images are produced not via the act of our conscious will. But why think that one's conscious will necessarily renders an imagined image less forceful and less vivacious than an imagined image brought forth without the conscious will being involved? I see no reason to answer this question in the affirmative. Thus, I don't yet see a reason to endorse this position over mine. That is, I don't yet see a reason to think that from a first person perspective there is an intrinsic difference between a percept and an imaged image brought forth willingly or unwillingly. 
could tell a story about my perceptions that had my father jumping on a plane for a surprise visit. Notice that a coupling has occurred between the sensory and conceptual. It was my perceptions in combination with the story I told about these perceptions that did the justifying here.

A similar kind of coupling has also occurred with the imagination. Because of the problem of indeterminacy, I can't conclude that I have imagined $\mathrm{p}$ just by considering the images I conjure up. Instead, within the confines of my best explanation and while ignoring the fact that I called forth these images, I must be able to offer an account of or story about these images that justifies my taking them to be veridical perceptions of $\mathrm{p}$. If I can tell such a story, then I am justified in concluding that I have imagined $p$. Again, it is these images in combination with the stories I tell about them that does the justifying.

Thus, we are no longer employing these two methods of conceiving separately. Rather, we are employing them together to negotiate the problem of indeterminacy. ${ }^{24}$ Given this, it isn't enough to

${ }^{24} \mathrm{My}$ theory of the imagination is similar to Peacocke's. Both Peacocke and I hold that while the images we call forth are integral to determining the content of our imagination, they alone don't determine this content. I argue that this content is also determined by the stories we tell about these images. Peacocke similarly argues that this content is determined by our "S-imaginings." (Peacocke, (1985): 25) To S-imagine is to set forth a condition on the world that is being imagined. So, for example, to imagine a suitcase behind which a cat is completely obscured, one must call forth an image of a suitcase and then S-imagine that there is a cat behind it.

I take myself as extending Peacocke's theory. Peacocke places only one limitation on what we can S-imagine. While multiple S-imaginings can apply to any one instance of our imagining something, Peacocke holds these multiple S-imaginings can't contradict each other. So, I can't S-imagine that there is a cat behind this suitcase and also S-imagine that there isn't a cat so hidden. But I contend that there needs to be other limitations placed on our S-imaginings. For as it stands now, our S-imaginings aren't confined by the images we call forth. So, I can call forth an image of a table with a round top and S-imagine that this tabletop also has the properties of a square. Now, maybe round-square tables can be imagined, but this is clearly a cheat.

Peacocke is skeptical about the imagination's ability to solve philosophically complex problems. But he does not dismiss the imagination as a guide to possibility. Unfortunately, he doesn't explain the conditions under which the 
determine whether either of these methods by themselves provides us with a guide to p's possibility. We must instead look at both of these methods and see whether or not together they provide us with a guide.

Let's consider a simple case. I wonder whether it is possible for my dog, Seamus, to escape his pen. He hasn't yet, but could he? In response to this question, while looking out into his pen I conjure up images that are relatively forceful and vivacious. These images are of a dog that looks like Seamus digging a mighty hole and running free. Along with these images, I tell a story within the confines of my best explanation that would justify my taking these images to be veridical perceptions (if these images had come to me in such a way that I didn't know their origins). In this story, I explain how, given that the top soil around my house is both very thick and very loose, Seamus is able to dig a hole deep enough for him to crawl out under the fence and hence attain his freedom.

Let's assume that up until the point at which I imagined Seamus, there was a possible world where my epistemic twin resided. Our epistemic twins are those individuals that exist in some possible world who share those first person epistemic properties and states that are relevant to our beliefs and our justificatory practices. From the first person perspective, they believe what we believe, experience what we experience, and reason as we do in the actual world. ${ }^{25}$ Of course, in particular instances, two twins may be similar in other ways, but not as a direct consequence of their being epistemic twins. ${ }^{26}$

imagination can fulfill this role. This is what I am trying to do here. To work with Peacocke's terminology, I am arguing that the imagination can in some cases provide us with a guide, if the purpose of our S-imaginings is to offer an account of the images we call forth within the confines of our best explanation.

${ }^{25}$ See footnote 19.

${ }^{26}$ Epistemic twins are different both from Kripke's epistemic counterparts and Putnam's twins. For Kripke, an epistemic counterpart is an individual that exists in a possible world. This individual possesses many of the traits that are used in the actual world to identify a particular person (R) as R. But yet this individual is not in fact $R$. By contrast, epistemic twins enjoy the same first person epistemic properties and states, but they need not share any other traits. A twin on Putnam's Twin Earth, like an epistemic twin, will share all the same psychological states as her doppelganger in the actual world, but, unlike epistemic twins, Putnam's twins must also be "molecule for molecule identical." 
Thus, up until the point at which I imagined Seamus, my epistemic twin, let's call her Rebecca, enjoyed the same first-person epistemic properties that I enjoyed. Let's further assume that a difference emerges between Rebecca and me with respect to these images of Seamus. Specifically, let's assume that while I consciously intended to imagine Seamus, Rebecca formed no such conscious intention. Instead, these images came to Rebecca unbidden. Thus, maybe Rebecca unconsciously called forth these images of Seamus, maybe she veridically perceived Seamus, or maybe instead she was a victim of an optical anomaly.

Very little has been specified about the metaphysical make up of Rebecca or Rebecca's world. I have assumed that Rebecca's world is a possible world and I have assumed that in this possible world images of Seamus's escape have come to Rebecca without her engaging her conscious will. But nothing else has been specified about Rebecca or her world. Clearly, there are many questions to be asked here about these assumptions. But let's put these questions aside to see what follows.

What should be obvious is that Rebecca is justified in believing that Seamus has escaped his pen. To explain, at the point at which these images of Seamus came to Rebecca and me, Rebecca should still be considered my epistemic twin for all intents and purposes. For at this point, Rebecca differs from me epistemically in only one way. My images of Seamus were accompanied by my consciously willing myself to have these images, while Rebecca's images were not so accompanied. But in every other way, her introspectible experiences of these images were like mine. They had the same content and they were as forceful and vivacious as my own. Moreover, the fact that Rebecca's images were not accompanied by a conscious intention to imagine would not have caused her to modify either her best explanation or how she employed her best explanation. ${ }^{27}$ Thus, she still employs her (and hence my) best explanation just as I

Putnam, Hillary, Reason, Truth, and History (Cambridge: Cambridge University Press, 1981): 18.

${ }^{27}$ I know that Rebecca would not here modify her best explanation because up until this point Rebecca and I were in fact epistemic twins. Thus, I know the conditions under which she would modify her best explanation and these conditions have not been met here. 
would employ it. Finally, in virtually every respect, her belief system is isomorphic with mine. To an overwhelming extent, we two share the same beliefs and we gather, sort, and combine these beliefs in the same ways.

Given that Rebecca should still be considered my epistemic twin, the conditions under which she is justified in taking an image to be a veridical perception are the same for her as for me. I am justified in taking an image to be a veridical perception if it is sufficiently forceful and vivacious, and if it is not accompanied by the conscious intention to imagine. In addition, I must also be able to account for that image as a veridical perception given my best explanation. Above, it has already been established that Rebecca's images of Seamus possess all of the relevant properties. They were sufficiently forceful and vivacious, and (unlike my images of Seamus) they weren't accompanied by the conscious intention to imagine. Moreover, given that Rebecca and I still employ the same best explanation, she (like me) can account for these images as veridical perceptions. Her story (like mine) involves loose dirt and deep topsoil. Thus, Rebecca is justified in taking these images to be veridical perceptions of Seamus's escape. This means that there is a possible world in which my epistemic twin is justified in believing that Seamus has escaped his pen.

Unfortunately, the mere fact that Rebecca is justified in believing that Seamus has escaped doesn't alone justify my belief that it is possible for Seamus to escape. For me to be so justified, I need some reason to base my beliefs on Rebecca's. Specifically, I need to be able to consider Rebecca a reliable witness with respect to the goings on in and around her. To be a reliable witness, first, she must have reasoned well when forming her beliefs about Seamus. And second, she must not be epistemically impaired. For example, I must not suspect that Rebecca regularly ingests psycho-tropic drugs. For if she did, I couldn't trust that her perceptions reflected what was actually in her world.

I can't help but think that Rebecca has reasoned well here. To think otherwise, I would have to conclude that she reasoned differently from the way I would have reasoned if I were in her situation. And I would have to conclude that she reasoned poorly in this situation. But Rebecca employs my best explanation as I employ it. She 
can't reason differently from me. And I certainly won't ever judge her to be reasoning poorly, since she reasons as I do. Thus, in my estimation, there is no way that she could have failed to satisfy this first condition.

What then of the second condition? Do I have any reason to believe that Rebecca was epistemically impaired at the time at which these images of Seamus came to her? Again, Rebecca is for all intents and purposes my epistemic twin. My experiences are, for the most part, her experiences. Thus, if I believe myself to be epistemically impaired, I have reason to believe that Rebecca is epistemically impaired as well. But I have no such reason. My vision is 20/20. And neither shadow nor direct sun was distorting or impairing my vision at the time in question. In addition, as far as I know, there are no and there were no holographs in my backyard. Finally and more importantly, I didn't consume any mind altering substances prior to these images of Seamus coming to me. Thus, because I suffered no impairments, I have no reason to believe that Rebecca's epistemic abilities were impaired.

But doesn't the fact that I imagined Seamus's escape give me reason to believe that, unbeknownst to Rebecca, she was imagining as well? If it does, then I must consider Rebecca to be epistemically impaired. She must have suffered from some sort of hallucination. In response to this, note that I know that I imagined Seamus's escape largely because I consciously intended to imagine his escape. But Rebecca formed no such conscious intention. Thus, what justifies my conclusion that I was imagining wasn't true of Rebecca. Moreover, the fact that Rebecca formed no such conscious intention doesn't mean that this intention was formed unconsciously. It might have been; but as I said before, we don't know how and why these images came to Rebecca. Thus, nothing justifies the conclusion that Rebecca imagined here. ${ }^{28}$

${ }^{28}$ Some might argue that what justifies this conclusion is the fact that Rebecca's world is seemingly so similar to my world. This similarity, coupled with the fact that I imagined this escape, supposedly gives me reason to believe that Rebecca also imagined this escape. Putting aside the question as to how similar Rebecca's world is to my world, what we do know about how Rebecca's world differs from mine precludes the success of this argument. Rebecca's images (unlike mine) weren't accompanied by the conscious intention to imag- 
Given this, I can conclude that in this situation Rebecca has satisfied the two conditions associated with being considered a reliable witness. I have every reason to believe that she has reasoned well and no reason to think that she was epistemically impaired. Thus, because Rebecca is in my estimation a reliable witness, I am justified in basing my beliefs on her beliefs.

Some won't be satisfied with this argument, claiming that in order to establish Rebecca's reliability, I have to do more than merely satisfy these two conditions. I must as well uncover some reason to think that Rebecca's beliefs are true. For her beliefs could all be false and if they are, then surely I shouldn't base my beliefs on hers. But keep in mind that Rebecca is my epistemic twin. In every way but one, she has the same experiences, beliefs, and justificatory practices as I do. Now, because Rebecca is my epistemic twin, as far as I am concerned Rebecca's reliability and my reliability rise and fall together. Thus, if I have reason to doubt Rebecca's reliability, I will equally have reason to doubt my reliability. So, for me to entertain the possibility that Rebecca's beliefs are all reasonable but false, I must also entertain the possibility that my beliefs are reasonable but false. Moreover, to dismiss this possibility, I will have to establish that I am somehow immune from skepticism. In other words, I will have to solve the problem of skepticism. But surely I can't be required to do that here.

Putting this in another way, those who worry about Rebecca's reliability never raise questions in regards to my reliability and instead accept it as a given. But what justifies them in limiting their skeptical concerns to Rebecca? How is it that these concerns arise only in this possible world but not in the actual world? The fact is once we play the skeptical card, it can be played over and over again, such that any epistemological question of concern here will have to be put aside to await skepticism's resolution. Thus, we have a choice. Either we assume that I am reliable and concede that Rebecca, for the reasons I offer, is reliable as well, and then proceed to consider the viability of my modal epistemology. Or, by raising the specter

ine. On my and hence Rebecca's best explanation, images that aren't so accompanied are typically (though not always) deemed veridical. Thus, this argument from similarity doesn't go through. 
of skepticism, we question both Rebecca's reliability and my own, abandon the study of modal epistemology altogether, and turn to the problem of skepticism. Other epistemologists have chosen the first option and it is the choice I make as well.

So, let us concede that I am not required to solve the problem of skepticism and that hence Rebecca (like myself) is to be considered reliable. Given this, the fact that Rebecca is justified in believing that Seamus has escaped justifies my belief that in Rebecca's world Seamus has escaped. Thus, I am justified in believing that there is a possible world in which my dog has escaped his pen. So, if the assumption that began this example is acceptable, we have here an instance of my justifying my belief in what is possible based on the images I have called forth and on the story I have told. But is this assumption acceptable?

I assumed above that there is a possible world in which images of Seamus's escape have come to Rebecca without their being accompanied by her conscious intention to imagine. I have made no other assumptions about this world. Moreover, this assumption doesn't logically imply that in this world Seamus really did escape his pen. For again, this assumption doesn't say much of anything about the metaphysical constitution of Rebecca or her world. In fact, this assumption is compatible with Rebecca having unconsciously imagined Seamus, with her having veridically perceived Seamus, and with her being the subject of an optical illusion. Thus, I can't be charged with begging the question. But, even so, do I have any reason to believe that such images have come to Rebecca unbidden?

Images of various kinds come to me without my conscious will being involved. This is true not only of my perceptions and the optical illusions I suffer from but of my imaginings as well. I accidentally fall into most of my daydreams while I am steadfastly intending to do my work. And, of course, given that Rebecca is my epistemic twin, the same must be true of her. Thus, the assumption that that these images have come to Rebecca without her forming any conscious intention seems perfectly acceptable.

Moreover, any sensory experience we conjure up via our imagination is one that could have come to us in some way or other through a pathway associated with our sensory faculties. For what we imag- 
ine is constructed out of what we have at some point perceived. So it stands to reason that those sensory experiences produced by the imagination could have been produced via the workings (standard or otherwise) of our sensory systems. Thus, the fact that I just imagined Seamus's escape means that there is a possible world in which Rebecca has either veridically or non-veridically perceived Seamus's escaped. And, of course, if an image is a product of our perception (whether veridical or not), then it has not been consciously willed. Thus, in this possible world Rebecca has had images of Seamus's escape come to her without her conscious will being involved.

Note that above I am using my knowledge of what is possible to justify my main assumption. I know that it is possible for images of various kinds to come to me without my consciously intending anything. I know as well that what we can imagine we could have perceived. Thus, I see no problem in concluding that these images of Seamus came to Rebecca without being accompanied by a conscious intention to imagine. But even so, I can't be charged with begging the question. For nothing above implies that it is possible for Seamus to escape. To see this, it is important to note that I am not employing 'perceive' as a success verb. I am not assuming that if Rebecca perceived Seamus's escape, in her world he did in fact escape. Instead these perceptions could be the product of an optical anomaly and hence not represent any fact about her world.

In the end, there is nothing illegitimate about my using the beliefs I do have about what is possible to justify other beliefs just so long as I beg no questions. Admittedly, a complete modal epistemology would explain how I came to know about these other possibilities. And, as I have suggested, some of this evidence comes directly from our own (actual) experiences. But my goal at this time isn't to set forth a complete modal epistemology. It is only to offer an account of how in some cases conceivability can provide us with a guide to possibility and this I have done. ${ }^{29}$

Thus, to summarize, it is the coupling of our abilities to conjure up images with our abilities to tell certain kinds of stories about these images that enables us in some cases both to negotiate the problem

${ }^{29}$ For a fuller discussion of the relationship between imagination and perceptions, See Hanrahan, 2007. 
of indeterminacy and to use conceivability as a guide to possibility. Say that I can conjure up images of something that looks like p. Say that I can also tell a story within the confines of my best explanation that would justify my taking these images to be veridical perceptions of $p$ if I ignore the fact that I consciously willed these images. Well, then not only can I conclude that I have imagined $p$ here, but I can also justify my belief that $p$ is possible. ${ }^{30}$

Obviously, I can't justify all of my beliefs in regards to what is possible via this epistemology. Consider again the example of Seamus. I imagined Seamus's escape as I was looking out into my backyard where his pen is. What if instead I had imagined his escape while I was doing my shopping? In such a case as this, if these images had come unbidden to my epistemic twin while she believed herself to be shopping, she would not be justified in taking them to be veridical. Instead her best explanation (like mine) would demand that

${ }^{30}$ Shoemaker has a view similar to mine in so far as he holds that if we can imagine justifiably believing that $p$, this provides us with reason for thinking that $p$ is possible. He further argues that though the imagination can provide us with a guide to possibility, we need to be careful how we imagine $p . P$ isn't to be imagined merely from the first person perspective; it is also to be imagined from the third person perspective. For often when $p$ is imagined from this perspective, it is revealed that what has been imagined from both perspectives begs the question.

But in terms of my modal epistemology, what exactly does it mean to imagine from the third person perspective? Return to the example of Seamus. Do I need to imagine from the outside a scenario in which Rebecca watches Seamus escape? If I do, then Shoemaker is right. I have begged the question here. I could only take myself to have imagined this if I assume that it is possible for Seamus to escape. But isn't the requirement to imagine such a scenario tantamount to denying the role of the reliable witness? This requirement basically demands that I rely on Rebecca's reports only if what she has witnessed is in some sense witnessed by another. But this can't be right; either we rely on witnesses or we don't, and if we do, we need not witness what they witness.

Alternatively, it could be that what needs to be imagined here is Rebecca's reliability being evaluated from a third person, objective perspective. I take Rebecca to be reliable but can I imagine others doing so? To this, note again that Rebecca is my epistemic twin. Thus, I would have reason to think that others would doubt Rebecca's reliability only if I have reason to think that they would doubt mine. I have no such reason, so this imaginative exercise does not undermine my conclusion that Rebecca is reliable. Hence, I can base my belief in the possibility of Seamus's escape on Rebecca's beliefs. 
she ascribe these images to an overactive imagination. Thus, at that moment while in the grocery story I couldn't via the above argument justify my belief that Seamus's escape was a possibility. But, via this epistemology, I could justify my belief that it was possible for the store to have run out of $1 \%$ milk or my belief that it was possible for there to be a sale on Hershey's Quik.

We see, then, that via this method we are only able to justify those modal beliefs that refer to variations in our immediate perceptual surroundings. Thus, this method as it stands now is limited. But keep in mind that at this time, we have no viable modal epistemology of any kind whatsoever. The only contenders out there-modal intuitionism and set-constructionism-suffer from deadly flaws. ${ }^{31}$ So, even though this modal epistemology is limited, it does represent serious progress. Also keep in mind my goals for this paper. I wanted to construct a modal epistemology that could explain our everyday uses of conceivability as a guide to possibility. I wanted to explain why, for example, I was justified slowing down as a consequence of my imagining a police car's flashing blue lights in my rear view mirror. Via an argument similar to the one presented above, I can now do just that.

\section{Counterexamples and Incompleteness}

So, my modal epistemology as it stands can't be used to justify all of our modal beliefs. This, in and of itself, isn't a reason to reject my epistemology. But might there be such a reason? To close this paper, I want to consider two counterexamples to my theory before returning to the problem of incompleteness.

First, it seems as if my theory is open to some standard counterexamples brought against any modal epistemology. For example, I can imagine turning on the TV and being informed by the host of some morning news program that Hesperus is not Phosphorus. A reporter explains that astronomers have discovered an astronomical body that appears and disappears in the night sky about every 1,000 years. An astronomer then comes on the telly and notes that the last time this body appeared was during antiquity and she fur-

${ }^{31}$ See Hanrahan, 2007. 
ther explains that where it appeared in the night sky back then was approximately where Venus would appear if you were looking at the sky from the Mediterranean. Hesperus is not Venus, this scientist concludes; hence Hesperus is not Phosphorus.

Now the fact is, I learn a fair amount about my world via the news. Thus, if such reports can justify my beliefs about my world, they must also justify my twin in her beliefs about her world. So, my twin is seemingly justified in believing that Hesperus is not Phosphorus. Thus, given my modal epistemology, I am justified in believing that it is possible that Hesperus is not Phosphorus. But, of course, this is in fact an impossibility. So, here we seemingly have a counterexample to my theory.

But this example presents no challenge to my theory. To see this, consider that there are in fact two ways one could construe the scenario described above by the imagined reporters and scientists. On one hand, suppose 'Hesperus' and 'Phosphorus' rigidly designate Venus. Then the proposition "Hesperus is Phosphorus" is necessarily true. Now, if this proposition is necessarily true, and I and hence my twin are aware of this fact, then reason demands that we (my twin and myself) take this scenario not to confirm the proposition that "Hesperus is not Phosphorus," which, as my twin and I both know, describes an impossibility. Rather, reason demands that we take this scenario to confirm the possible truth that "At different times people have used the term 'Hesperus' to designate something other than Venus." But such a conclusion does not challenge the viability of my theory. On the other hand, these terms could be used in such a way that they don't rigidly designate Venus. And in fact this is how these terms are being used above. After all, it gets to be a counterexample only in virtue of the fact that in that scenario Hesperus is not Venus. But then there is no necessary truth at issue here such that this scenario would allow me to confirm an impossibility. Thus, either way of taking this scenario poses no threat to my theory. ${ }^{32}$

${ }^{32}$ It is true that my theory is not designed to test claims concerning a posteriori identities. After all, it is built on our accounting for our imagined experiences as veridical perceptions via inferences to our best explanations. But the testing of such claims has dominated the discussion of modal epistemology, especially given how this discussion has played out in the context of the mind/ body debate. As a consequence, a kind of myopia has been imposed upon us 
Let's now to turn to the second counterexample to my theory. I solve the problem of indeterminacy via inferences to the best explanation. I argue that I am justified in taking an image to be of $p$ despite the fact that that image is indeterminate if (upon ignoring the fact that I formed the conscious intention to imagine) I could give an account of that image via my best explanation that would justify my taking it to be veridical perception of $p$. But this solution to the indeterminacy problem leads to certain counter-intuitive conclusions.

Say I want to imagine my uncle mowing my lawn, instead of my father. An image appears before my mind's eye of a man who looks like my uncle. As we know, this image also resembles my father. Using the procedure described above, I am not justified in taking this image to be of my uncle. Rather, I am only justified in taking it to be of my father. Hence, it seems I can't imagine my uncle mowing my lawn. But this runs counter to our intuitions: of course I can imagine either my father or my uncle mowing my lawn.

Keep in mind, though, that justification comes in degrees. Thus, my best explanation doesn't preclude me from concluding that this image is of my uncle; I am just less justified in concluding that it is of my uncle as compared to my father. In terms of my modal epistemology, this means I have more reason to think that my father might mow my lawn than my uncle. But given my uncle's attitude towards lawn care and given where he lives, this conclusion conforms to my intuitions. ${ }^{33}$

Moreover, as I have said, it might be best to think of my solution to the indeterminacy problem as specific to the task of providing ourselves with a guide to possibility, especially given this last objection. Thus, when we are imagining for the purpose of establishing p's modal status, the content of what has been imagined is to be determined via an inferences to our best explanation. When imagining for other purposes, other requirements might be substituted; perhaps in some cases a mere appeal to our intentions in imagining is sufficient. So my general ability to imagine my uncle mowing my lawn isn't in jeopardy here.

philosophers. By focusing solely on such claims, we have ignored the modal claims that are at the center of our everyday concerns. But these are exactly the sorts of claims that interest me and the ones my epistemology addresses well.

${ }^{33}$ See footnote 12,16 , and 18 
Let us finally turn to the problem of incompleteness. In my modal epistemology, it seems as if the images we call forth do nothing more than prompt us to tell a story about $p$. These images seemingly do nothing to justify our belief that $p$ is possible. But if this is the case, then my modal epistemology is nothing new. In the end, I am just trying to justify my belief that $p$ is possible by describing what I hope is a possible world in which $p$ is true. Here though is where the problem of incompleteness and its solution come to the fore. If my modal epistemology is nothing new, if in other words I am merely trying to justify my belief that $p$ is possible by describing a possible world in which $p$ is true, then my modal epistemology must also suffer from the problem of incompleteness. Any description I give of a world will always be incomplete. Consequently, I can't be sure that this description when completed won't contain a contradiction. Thus, I can't be justified in believing that $p$ is possible based on this description alone.

But, in telling such a story, I am not trying to describe a possible world. If I was, the above objection would hold. Rather, in telling this story, I am offering an explanation that justifies my taking the images I have called forth to be veridical perceptions of $p$. This explanation serves two purposes. First, it is because I can offer this explanation that I am justified in taking these images to be images of p. Second, my ability to offer this explanation is what justifies my belief that my epistemic twin has such an explanation at her disposal. And, as I have explained, because she too can offer this explanation, she is justified in believing that the images before her mind's eye are veridical perceptions of $\mathrm{p}$. Now, I can't help but consider my epistemic twin to be a reliable witness. Thus, the fact that she is so justified provides me with the necessary justification for my belief that $p$ is possible.

Consider how inferences to the best explanation work when what needs to be justified is a belief we hold about the actual world. In such a case, there is no requirement that our best explanations be complete. And, obviously, completeness isn't required with respect to the account we give of the perception in question. On both levels, incompleteness is allowed for here. That is, despite these various incompletenesses, inferences to our best explanation are still taken to justify those beliefs which concern the actual world. And, importantly, these inferences are taken to justify these beliefs, even though 
we recognize that these failures of completeness may hide unsolvable problems. Given that incompleteness does not trouble us when we employ inferences to the best explanation to justify our beliefs about the actual world, what reason do we have to let it trouble us when we use such inferences to justify our beliefs about possible worlds? I can identify none. Hence, the incompleteness objection has been addressed.

Thus, we see here that the images we call forth and the stories we tell mutually reinforce each other and enable us to address the problems of incompleteness and indeterminacy. I can take the images I call forth as images of $p$ (despite the fact these images are indeterminate) if I can tell a story within the confines of my best explanation that justifies my taking these images to be veridical perceptions of $p$. I can take these same stories-in combination with these images-as providing me with a guide to p's possibility (despite the fact that these stories are incomplete) because these stories justify my twin's belief that these very same images are veridical perceptions. And it is in the end her justified belief about these images that justifies my belief that $p$ is possible.

Where then does this leave us? I have given an account of our more everyday uses of conceivability as a guide to possibility. I have also explained how in these cases we can solve the problems of indeterminacy and incompleteness. The task ahead is to figure out how this modal epistemology can be extended to justify more of our modal claims. But this task is best left for another paper. ${ }^{34}$

${ }^{34}$ I would like to thank Professor Walter Ott who has worked with me on every aspect of my theory on modal epistemology. 